\title{
GABA Involvement in Memory Consolidation: Evidence From Posttrial Amino-Oxyacetic Acid
}

\author{
R. J. KATZ and L. LIEBLER
}

Mental Health Research Institute, Department of Psychiatry, University of Michigan Medical Center, Ann Arbor, Michigan 48109, U.S.A.

Abstract. In order to assess the possible effects of central GABA activation on the consolidation of shock avoidance, the GABA-T inhibitor amino-oxyacetic acid (AOAA) was administered posttrial to adult male rats. Learning was assessed over nine widely spaced sessions of 20 trials each. AOAAtreated animals showed learning within sessions and a lack of consolidation across sessions. Controls, on the other hand, showed learning both within and across sessions. This evidence agrees with previous reports suggesting GABA involvement in memory processes.

Key words: AOAA - Consolidation - GABA Memory

A variety of reports have suggested the involvement of GABA neurons in memory consolidation. On the one hand, picrotoxin, a blocker of GABA neurotransmission, reportedly facilitates the acquisition of maze learning and other learning tasks (e.g., Breen and McGaugh, 1961; Garg, 1970; for more extensive reviews see Essman, 1971; Dawson and McGaugh, 1973). On the other hand, a number of reports have failed to replicate this finding (see above reviews), and localized CNS injections of GABA blockers may interfere with rather than facilitate consolidation (Kim and Routtenberg, 1976). In addition, a number of clinical reports have suggested that enhancement of gamma-aminobutyric acid (GABA) by chemotherapy may improve the learning ability of retarded or emotionally disturbed children (De Souza Compos, 1968; Rossi, 1972).

No studies to date, to our knowledge, have examined the effects of GABA enhancement on memory consolidation in animals. The present report therefore attempted to affect learning through such means. The drug used was amino-oxyacetic acid (AOAA), an inhibitor of GABA catabolism (Perry and Hansen, 1973; Grimm et al., 1975), and its effects were examined on two-way shuttlebox avoidance learning, a task often used in consolidation experiments.

\section{MATERIALS AND METHODS}

Subjects. Subjects were 17 adult male Sprague Dawley rats (Charles River Farms, Portage, MI), each weighing 350-550 g. All subjects were housed individually with food and water available ad libitum and normal lighting cycles of $12 \mathrm{~h}$. Two experimental and three control animals were eliminated from the experiment during the course of testing because one subject died due to causes unrelated to the experiment, two learned an avoidance response that could not be measured by the designated shuttle response (i.e., perching upon a central barrier), and two showed experimental helplessness (i.e., a failure to learn to escape from shock in any trial). The final pool, therefore, consisted of seven experimental and five control animals.

Apparatus. Subjects were tested in a $27 \times 22 \times 48 \mathrm{~cm}$ shuttlebox (BSR/LVE No. 146/04) situated in an anechoic chamber to minimize experimental interference. The CS was provided by an overhead sonalert alarm, which emitted a $2.5 \mathrm{kHz}$ tone.

Drugs. Amino-oxyacetic acid (Sigma 4508) was administered $25 \mathrm{mg}$ / $\mathrm{kg}$ immediately (i.e., less than $60 \mathrm{~s}$ ) after each session, and control rats received a vehicle injection in an identical manner. All injections were administered i.p. $1 \mathrm{ml} / \mathrm{kg}$ in $0.9 \%$ sodium chloride solution. Drug dosage was based on previous biochemical and behavioral studies (e.g., Grimm et al., 1975; Wood and Peesker, 1973).

Procedure. Subjects were given 20 trials per day for nine sessions. Each trial consisted of a 5-s CS (tone) followed by a 30 -s US (pulsed shock). The shock US consisted of 15 regularly spaced $0.5 \mathrm{~s}$ pulses of $0.75 \mathrm{~mA}$ scrambled AC current delivered by LVE 113-33 shockers. Intertrial intervals ranged from $30 \mathrm{~s}$ to $3 \mathrm{~min}$. A minimum of $72 \mathrm{~h}$ intervened between sessions.

Statistical Analysis. Learaing curves for both experimental and control groups are presented as means and standard errors in Figure 1. For ease of presentation and analysis, data are grouped into five trial blocks, four per session. Initial visual inspection of the learning curves indicated a large difference in SE scores across 


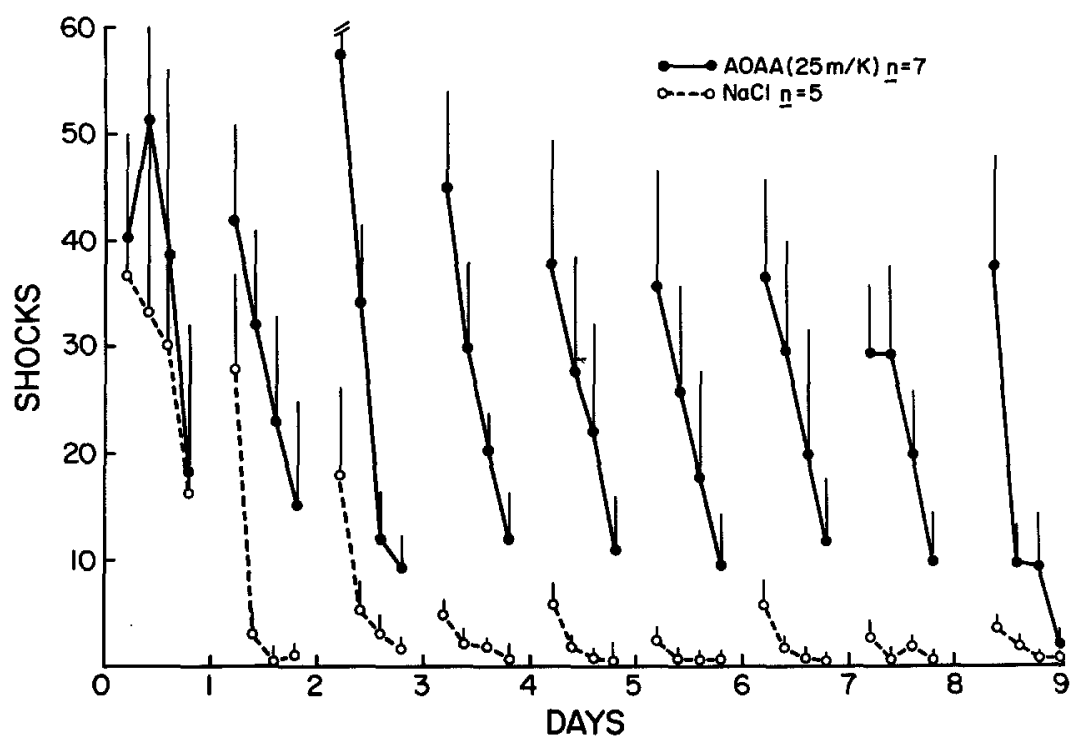

Fig. 1. Effects of posttrial AOAA on shuttlebox shock avoidance. Points: mean \pm SEM for number of shocks in five trial blocks during same session. Solid lines: AOAA-treated. Broken lines: vehicle-treated

testing conditions. Analysis was therefore based on the distributionfree technique of Jonckheere (1954) against ordered alternatives. It might be noted that the Jonckheere technique specifically assesses the ordering of events and thus is particularly appropriate for the analysis of learning or other processes in which sequential outcome is a consideration.

Statistical assessment of learning within sessions indicated substantial learning by both groups ( $\mathrm{S}$ values $=95,83$, respectively, for experimental and control groups $P<0.01$ ). Learning across sessions was tested by Jonckheere analysis upon the ordering of the initial block of trials of each session across the nine learning sessions, with the assumption that learning across sessions should result in an ordered decrease within this block. As Figure 1 indicates, the experimental group shows only marginal learning $(\mathrm{S}=8, P>0.05)$ while the vehicle-treated group shows evidence of learning across sessions $(\mathrm{S}=35, P<0.01)$.

\section{DISCUSSION}

It is apparent that both groups of subjects showed considerable learning within sessions. It is also clear, however, that in the experimental animals the administration of AOAA after a learning session produced a dramatic disruption of learning across sessions. This suggests that AOAA is a potent amnesia-producing drug. It might be argued, however, that the AOAAtreated group was disadvantaged due to processes unrelated to memory functions. For example, AOAA may produce ataxia in rats (Grimm et al., 1975), but AOAA-treated rats were not drugged during learning, and sufficient time elapsed between sessions for drug effects to dissipate. An inspection of the learning curves clearly indicates that the motor performance of the experimental animals was sufficient for substantial learning within sessions. Thus the lack of across-sessions learning may represent interference with the formation of long-term memory.

The ability of GABA-enhancing agents to decrease consolidation agrees with and complements the ability of GABA blockers to facilitate consolidation (e.g., Breen and McGaugh, 1961; Garg, 1970), although it is not necessarily consistent with clinical reports of GABA-induced memory enhancement (De Souza Campos, 1968; Rossi, 1972). These clinical reports often involved the concurrent administration of other drugs and the systemic administration of GABA itself as a dietary suppliment. GABA, however, is not believed to cross the blood brain barrier (Perry and Hansen, 1973). Finally, the clinical studies suffered from a number of methodological insufficiencies; i.e., they were not run in a double-blind design, nor did they examine consolidation as a separate experimental variable. Thus they may not be strictly comparable to the current results.

One other question might be raised regarding the biochemical specificity of GABA's anticonsolidation effect. GABA levels in the brain are not maximally increased until $4 \mathrm{~h}$ after injection (Grimm et al., 1975), and this implies a prolonged vulnerability of the memory trace. It might therefore be asked if a time course of consolidation of several hours is physiologically reasonable. Wood and Peesker (1973) have noted that GABA elevations are significant at $1 \mathrm{~h}$, although they subsequently continue to increase. Assuming that a significant albeit less than maximal increase in GABA is effective, a 1- rather than 4-h memory course must be accounted for. We feel a vulnerability of $1-2 \mathrm{~h}$ is reasonable in light of other evi- 
dence showing consolidation effects of several hours with many treatments (e.g., $1 \mathrm{~h}$, Schneider et al, 1969; $3-6 \mathrm{~h}$, Barondes and Cohen, 1968; $6 \mathrm{~h}$, Cherkin, $1969 ; 24$ h, Flexner et al., 1963). While shorter critical consolidation periods are also well established, these depend, as above, on model, treatment, and species. No a priori limit on consolidation time holds across conditions, and the present findings do not exceed the limits established by other treatments.

Heretofore, only limited attention has been devoted to the CNS events underlying GABA blockade or facilitation in relation to long-term memory effects. Recent histochemical and electrophysiological data may, however, offer some insight. It has been established that GABA may decrease the turnover of CNS noradrenergic and dopaminergic neurons (Fuxe et al., 1975). This turnover effect presumably depends on presynaptic (possibly axo-axonic) inhibition of monoaminergic cells (Suria and Costa, 1975).

Recently, it has also been shown that central NA neurons may mediate memory consolidation in the rat (e.g., Stein, 1975). If the observed experimental differences are a function of central GABA-NA interactions, it should be possible to reverse AOAA amnesia with clonidine or to reverse picrotoxin memory enhancement with phenoxybenzamine. We know of no published work addressing either of these hypotheses concerning GABA's pharmacological mode of action.

Acknowledgement. The authors gratefully acknowledge support provided by the National Institute of Mental Health (Grant MH 07417) to the first author.

\section{REFERENCES}

Barondes, S. H., Cohen, H. D.: Arousal and the conversion of short term to long term memory. Proc. Nat. Acad. Sci. 61, 923-929 (1968)

Breen, R. A., McGaugh, J. L.: Facilitation of maze learning with post-trial injections of picrotoxin. J. Comp. Physiol. Psychol. 54, $498-501(1961)$
Cherkin, A.: Kinetics of memory consolidation: role of amnestic treatment parameters. Proc. Nat. Acad. Sci. 63, 1094-1102 (1969)

Dawson, R. G., McGaugh, J. L.: Drug facilitation of learning and memory. In: The physiological basis of memory, J.A. Deutch, ed., pp. 78-104. New York: Academic Press 1973

De Souza Campos, Jr., M.: The effects of gamma-aminobutyric acid in combination with vitamin B6 on mentally deficient children. O. Hospital 73, 1647-1651 (1968)

Essman, W. B.: Drug effects and learning and memory processes. Adv. Pharmacol. Chemother. 9, 241-330 (1971)

Flexner, J. B., Flexner, L. B., Stellar, E.: Memory in mice as affected by intracerebral puromycin. Science 141, $57-59$ (1963)

Fuxe, F., Adnati. L. F., Bolme, P., Hokfelt, T., Lidbrik, P., Ljungdhal, A., Perez de la Mora, M., Ogren, S.-O.: The possible involvement of GABA mechanisms in the action of benzodiazepines in central catecholamine neurons. In: Adv. Biochem. Psychopharmacol., vol. 14, E. Costa and P. Greengard, eds., pp. 45-63 (1975)

Garg, M.: Combined effect of drug and drive on the consolidation process. Psychopharmacologia (Ber1.) 18, 172-190 (1970)

Grimm, V., Gottesfeld, Z., Wassermann, I., Samuel, D.: The level of GABA in the brain and locomotor behavior. Pharmacol. Biochem. Behav. 3, 573- 579 (1975)

Jonckheere, A. R.: A distribution-free k-sample test against ordered alternatives. Biometrika 41, 133-145 (1954)

Kim, H.-J., Routtenberg, A.: Retention disruption following posttrial picrotoxin injection into the substantia nigra. Brain Res. $113,620-625(1976)$

Perry, T. L., Hansen, S. : Sustained drug induced elevation of brain GABA in the rat. J. Neurochem. 21, 1167-1175 (1973)

Rossi, A. O.: Genetics of learning disabilities. J. Learn. Disabilities 5, 489-496 (1972)

Schneider, A., Kapp, B., Aron, C., Jarvik, M. E.: Retroactive effects of transcorneal and transpinnate ECS on sleep through latencies of mice and rats. J. Comp. Physiol. Psychol. 69, 505-509 (1969)

Stein, L. : Norepinephrine reward pathways : role in self stimulation, memory consolidation, and schizophrenia. In: Nebraska Symposium on Motivation, J. K. Cole and T. B. Sonderegger, eds., pp. $113-161$. Lincoln: University of Nebraska 1975

Suria, A., Costa, E. : Evidence for GABA involvement in the action of diazepam on presynaptic nerve terminals in bullfrog sympathetic ganglia. In: Adv. Biochem. Psychopharmacol., vol. 14, E. Costa and P. Greengard, eds., pp. 103-113 (1975)

Wood, J. D., Peesker, S. J.: The role of GABA metabolism in the convulsant and anticonvulsant action of AOAA. J. Neurochem. 20, 379-387(1973)

Received June 23, 1977; Final Version September 27, 1977 